\title{
Measurement of Oxygen Concentration in Static and Flowing Liquid Pb-Bi by Using Zirconia Based Sensor
}

\author{
Pribadi Mumpuni Adhi $^{1^{*}}$, Dianta Mustofa Kamal ${ }^{1}$, Muslimin ${ }^{1}$, Andrei Vilcu $^{2}$, Masatoshi \\ Kondo $^{3}$, Minoru Takahashi ${ }^{3}$ \\ ${ }^{I}$ Department of Mechanical Engineering, Politeknik Negeri Jakarta, Jl. Prof. G. A. Siwabessy, Kampus UI, Depok \\ 16425, INDONESIA \\ ${ }^{2}$ Politechnica University of Bucharest, \\ Str. Splaiul Independentei nr 313, District 6, Bucharest, 060042 ROMANIA \\ ${ }^{3}$ Laboratory for Advanced Nuclear Energy, \\ Institute Innovative Research, Tokyo Institute of Technology, \\ 2-12-1 Ookayama, Meguro-ku, Tokyo, 152-8550, JAPAN
}

( Received: August 15, 2018, Revised: December 21, 2018, Accepted: January 21, 2020 )

\begin{abstract}
Liquid Lead-Bismuth Eutectic (LBE) has been proposed as one of the coolant for the Generation IV nuclear reactor. However, the oxygen should be controlled adequately to suppress the corrosion rate of the LBE. A device called oxygen sensor made of zirconia as solid electrolyte has been used to monitor the oxygen concentration online in order to control the oxygen concentration. The principle of this sensor is based on electrochemistry method where the difference oxygen activitiy between reference electrode (RE) and working electrode (in liquid LBE) can make potential difference. The potential difference is measured by electrometer and can be converted into oxygen concentration based on Nernst equation. Iron $(\mathrm{Fe}) / \mathrm{Magnetite}\left(\mathrm{Fe}_{3} \mathrm{O}_{4}\right)$ was used as material for $\mathrm{RE}$ in this study. Measurement of oxygen concentration was conducted at $450-600^{\circ} \mathrm{C}$ for the static condition of $\mathrm{LBE}$ and around $390^{\circ} \mathrm{C}$ for the dynamic condition of flowing $\mathrm{LBE}$. The oxygen concentration for both two experiment conditions were set in oxygen saturated condition of $\mathrm{Pb}-\mathrm{Bi}$. The oxygen sensor based on zirconia solid electrolyte with $\mathrm{Fe} / \mathrm{Fe}_{3} \mathrm{O}_{4}$ as $\mathrm{RE}$ can measured the oxygen concentration in liquid LBE. The results showed that the measurement was agreed with the Nernst equation theoretical calculation.
\end{abstract}

Keywords: Liquid LBE, Oxygen concentration, Oxygen sensor, Zirconia

\section{INTRODUCTION}

Lead alloy consists of $44,5 \mathrm{wt} \%$ of lead $(\mathrm{Pb})$ and $55,5 \%$ of bismuth (Bi) or Lead-Bismuth Eutectic (LBE) has been proposed as promising candidate of coolant for Lead-Bismuth type fast reactor (LFR) and coolant and spallation target accelerator-driven transmutation system (ADS) [1]. The benefits of using LBE as a coolant: LBE has low melting point at $123,8^{\circ} \mathrm{C}$ and high boiling at $1670^{\circ} \mathrm{C}$ [2], has high scattering cross section, and does not react violently with air or water such as in sodium case. Therefore, LBE is easy to maintain

\footnotetext{
* Corresponding author

E-mail address: pribadi.adhi@mesin.pnj.ac.id
}

during the operation and the accident such as loss of coolant accident (LOCA) can be avoided.

However, besides its advantages, the liquid LBE has some drawbacks when using as a coolant in the nuclear reactor system. dengan material struktur pada suhu tinggi. Damage of structural materials due to corrosion kinetic such as dissolution of metal elements into LBE, penetration of LBE into structural material, and also oxidation of LBE itself are the main concern of this technology and need to be solved.

Control the oxygen concentration actively is necessary to suppress the corrosion problems. The upper limit of oxygen concentration that permitted in liquid $\mathrm{LBE}$ is equal to $\mathrm{PbO}$ formation potential and the lower limit for oxygen concentration is equal to $\mathrm{Fe}_{3} \mathrm{O}_{4}$ formation potential as shown in 
Fig 1. The oxygen concentration should be controlled between $3,1 \times 10^{-6}$ wt $\%$ dan $1,8 \times 10^{-8}$ wt $\%$. Active oxygen control can make self protective thin layer oxide on the surface of structural steel. Some methods can be used to control the oxygen concentration. Injection of mixture of $\mathrm{H}_{2} / \mathrm{Ar} / \mathrm{steam}$ into LBE $[3,4]$, controlling by solid $\mathrm{PbO}[5,6]$, or using oxygen pump [7] are some methods to control the oxygen concentration.

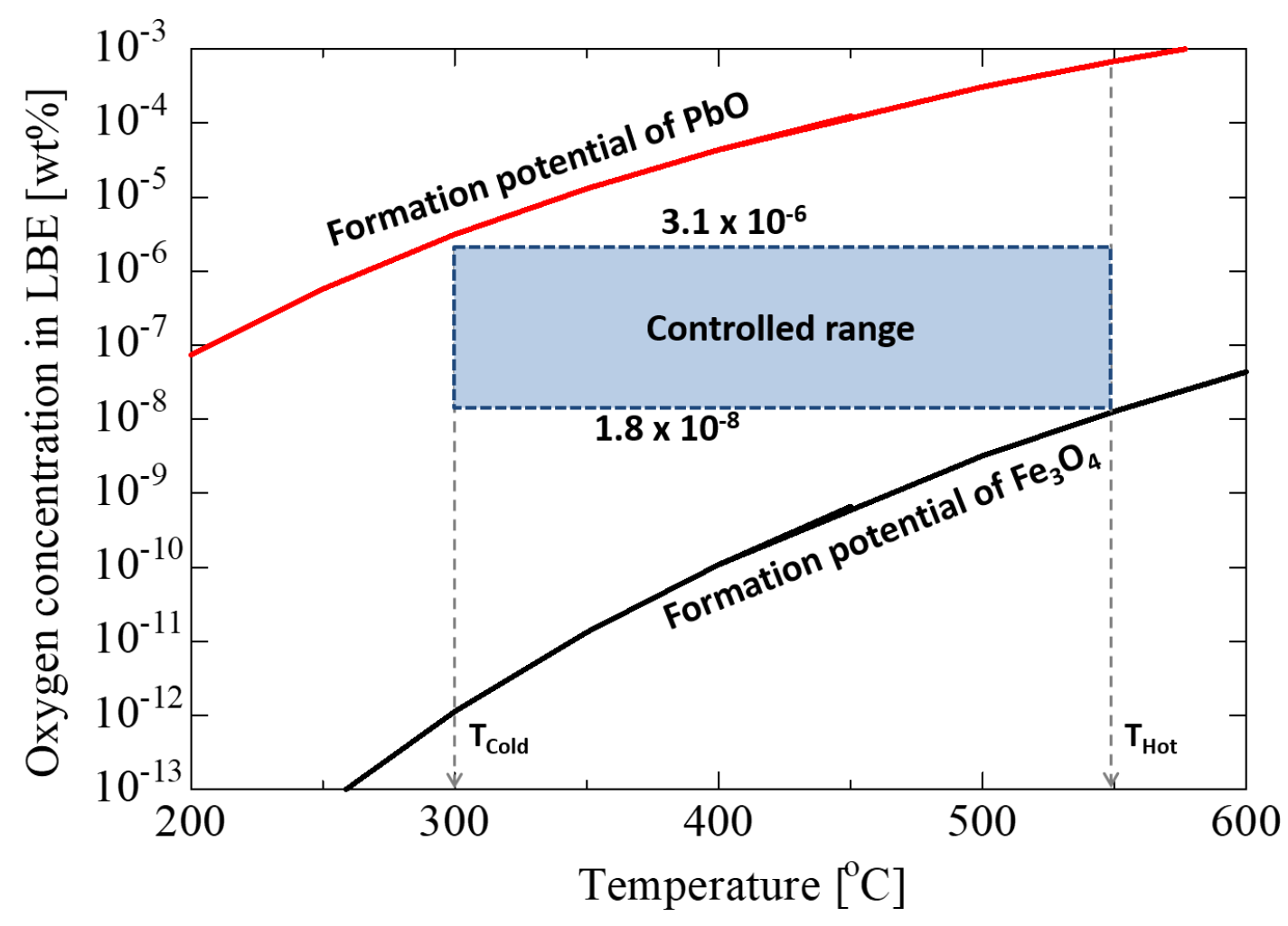

Figure 1. Oxygen control boundary of LBE cooled system

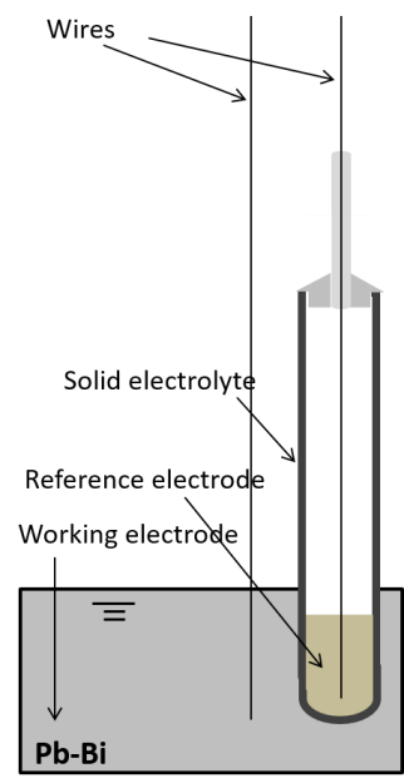

(a)

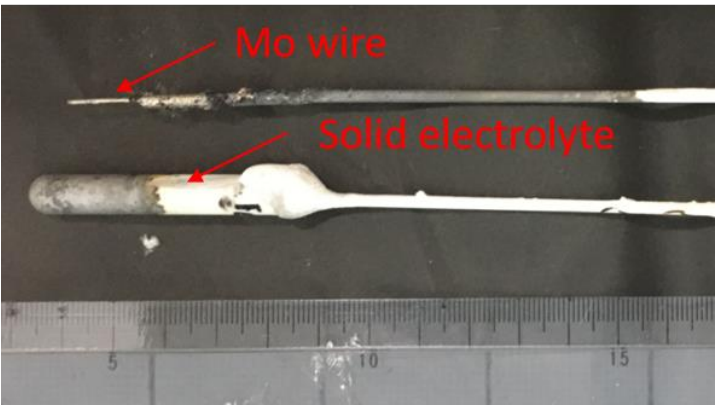

(b)

Figure 2. Oxygen sensor: (a) schematic figure. (b) example of oxygen sensor that has been used 
An instrument to measure dissolved oxygen concentration in LBE accurately is needed to perform active oxygen control. Oxygen sensor as an instrument for measuring oxygen online on LFR and ADS have been proposed and tested [8]. This sensor consists of three main components: reference electrode, solid electrolyte, and working electrode. These three components are schematically shown in Figure 2a. The reference electrode must have a fixed and known potential value at a constant temperature condition. This reference electrode can be made by mixing molten metal and its oxide (e.g. $\mathrm{Bi} / \mathrm{Bi}_{2} \mathrm{O}_{3}$ ); mixing solid metal powder and its oxide (e.g. $\mathrm{Fe} / \mathrm{Fe}_{3} \mathrm{O}_{4}$ ) with gas (initially air); or gas (usually air) which has a partial oxygen pressure which is still combined with the metal so that there is contact with the inner electrolyte surface (e.g. Pt/air).

The solid electrolyte used is zirconia ceramics $\left(\mathrm{ZrO}_{2}\right)$ which has been partially stabilized by the addition of magnesia $(\mathrm{MgO})$ or yttria $\left(\mathrm{Y}_{2} \mathrm{O}_{3}\right)$. These solid electrolytes must have high oxygen ion conductivity so that oxygen ions can be transferred through the material. The working electrode consists of metal wire which has good corrosion resistance which, made of molybdenum (Mo). Solid electrolyte and working electrode are immersed in liquid LBE at the time of measurement. Measurements are made through an open circuit and the potential difference between two wires is measured. An example of an oxygen sensor that has been used in this study is shown in Figure $2 b$.

The material selection of the reference electrode influences the performance of the oxygen sensor [9]. A good reference electrode must have a small impedance so that the sensor has a fast response time [10]. Comparison of the performance of sensors using $\mathrm{Fe} / \mathrm{Fe}_{3} \mathrm{O}_{4}$ and $\mathrm{Bi} / \mathrm{Bi}_{2} \mathrm{O}_{3}$ as reference electrodes has been carried out in previous studies on static conditions $[11,12]$. The performance of the sensor using $\mathrm{Fe} / \mathrm{Fe}_{3} \mathrm{O}_{4}$ shows the time to stabilize the sensor which is shorter than $\mathrm{Bi} / \mathrm{Bi}_{2} \mathrm{O}_{3}$. The testing of sensor under dynamic conditions, where the liquid LBE is flowing on the loop, using the oxygen sensor with $\mathrm{Fe} / \mathrm{Fe}_{3} \mathrm{O}_{4}$ as the reference electrode has not been tested yet.

In this study, the oxygen sensor using $\mathrm{Fe} / \mathrm{Fe}$ $\mathrm{O}_{4}$ material on the reference electrode was tested at LBE liquid at a temperature of $450-600^{\circ} \mathrm{C}$ under static conditions and temperatures of $450-500^{\circ} \mathrm{C}$ under dynamic conditions. The oxygen concentration is controlled to be saturated oxygen in $\mathrm{Pb}-\mathrm{Bi}$. The purpose of this study was to investigate the performance of oxygen sensors using $\mathrm{Fe} / \mathrm{Fe} 3 \mathrm{O} 4$ as a reference electrode in static and dynamic conditions by observing the potential different outputs produced by the sensor. The potential difference produced by the sensor is then converted to oxygen concentration in wt $\%$ using the Nernst equation.

\section{EXPERIMENTAL APPARATUSES AND CONDITIONS}

Experimental apparatus for static conditions is shown in Figure 3a. The apparatus consists of a stainless steel vessel and crucible made of ceramic $\left(\mathrm{Al}_{2} \mathrm{O}_{3}\right)$. The total amount of LBE in the crucible is $450 \mathrm{~g}$. The electric heater is wrapped around the outside of the vessel to heat and the PID controller is used to regulate the temperature. Thermocouples for measuring LBE temperature, sensor solid electrolytes, and Mo wires dipped in LBE. Ar gas is used as a protective gas so that outside air does not enter. Oxygen control using the mass-exchanger principle uses particle $\mathrm{PbO}$ of $4 \mathrm{~g}$. The LBE temperature is varied from $450^{\circ}$ to $600^{\circ} \mathrm{C}$ with a temperature rise of $50^{\circ} \mathrm{C}$.

The dynamic condition where LBE flows in a forced convection loop is shown in Figure 3b. The working principle of this loop has been described in a previous paper [14]. The loop consists of a high temperature region made of STBA26 steel $(9 \mathrm{Cr}$ $1 \mathrm{Mo})$ and a low temperature region made of SS-316 $(18 \mathrm{Cr}-12 \mathrm{Ni}-2 \mathrm{Mo})$. Liquid LBE is circulated using an electromagnetic pump and the flow rate is measured using an electromagnetic flow meter. The temperature of LBE in some places in the loop is monitored using a thermocouple. The focus of the research on the $\mathrm{Pb}-\mathrm{Bi}$ loop is on the oxygen sensor section. The placement of oxygen sensors was carried out after the $\mathrm{Pb}$-Bi flow passed a corrosion test section in a high-temperature region. Figure 4 shows the position of the oxygen sensor placement in the loop. The direction of the LBE flow is indicated using the arrow. LBE flow rates are arranged in loops with values ranging from $2.5-3$ $\mathrm{L} /$ minute. The maximum temperature permitted in this apparatus is $500^{\circ} \mathrm{C}$. For safety operations, the oxygen sensor is operated at temperatures around $390^{\circ} \mathrm{C}$. CADAC21 is used for the process of acquiring experimental data to the computer for both static and dynamic conditions. 


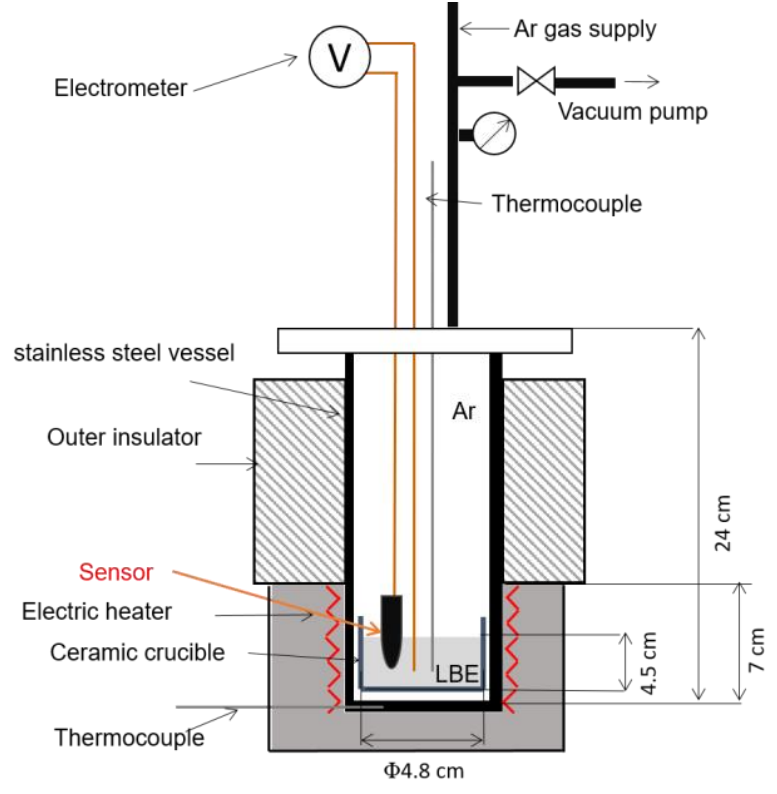

(a)

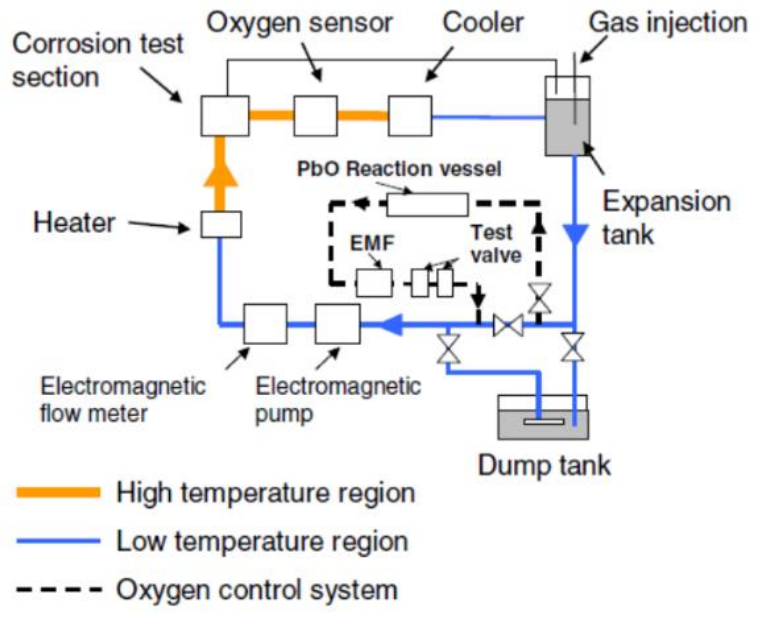

(b)

Figure 3. Experimental apparatuses: (a) in static condition. (b) Pb-Bi forced convection loop for dynamic condition [5]

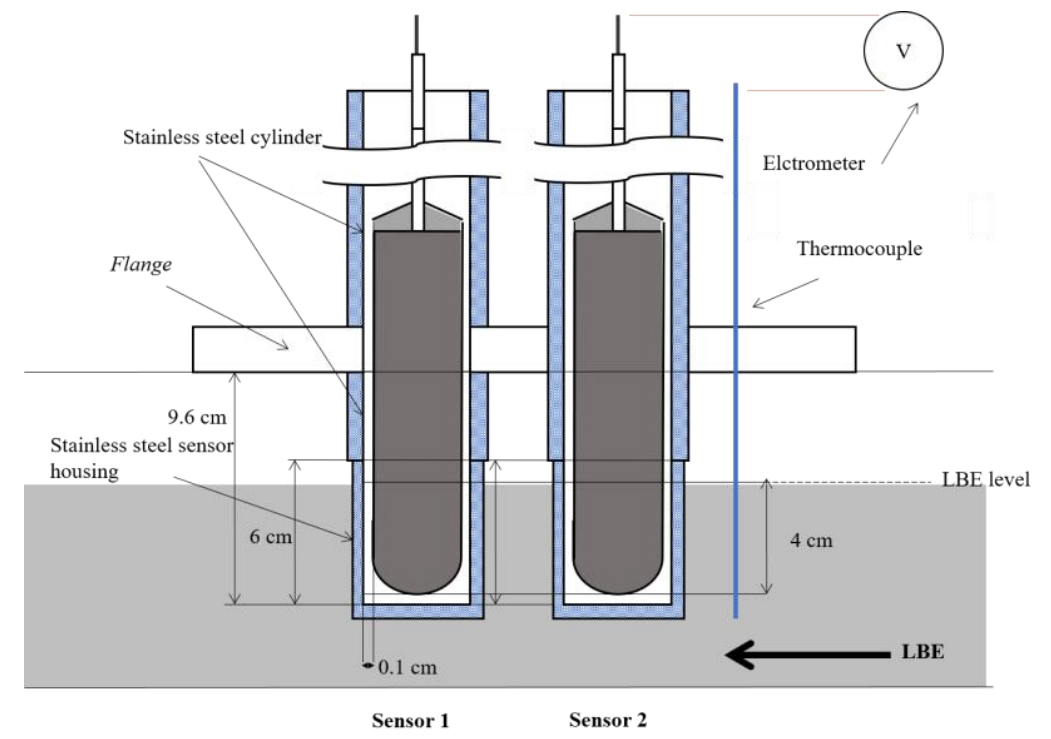

Figure 4. Position of oxygen sensor in $\mathrm{Pb}-\mathrm{Bi}$ forced convection loop

\section{STRUCTURE AND OXYGEN SENSOR WORKING PRINCIPLE}

Figure 5 shows the structure of the oxygen sensor used in this study. Magnesia Stabilized Zirconia (MSZ) is used as a solid electrolyte material with $\mathrm{Fe} / \mathrm{Fe}_{3} \mathrm{O}_{4}$ for reference electrodes. Details of how to make oxygen sensors have been described in the paper in the previous paper [11].
Oxygen sensors used in static conditions have dimensions: $5 \mathrm{~mm}$ inner diameter, $1.5 \mathrm{~mm}$ thick, and $50 \mathrm{~mm}$ long.

Sensors with a diameter of $5 \mathrm{~mm}$, thickness of $1.5 \mathrm{~mm}$, and length of $150 \mathrm{~mm}$ are used for dynamic conditions. Material for solid electrolytes for dynamic conditions using Yttria Stabilized Zirconia (YSZ). In principle, both materials have high ion conductivity values so that they can be 
used for oxygen sensors. The use of YSZ instead of MSZ in dynamic conditions is caused by low operating temperatures under dynamic conditions. YSZ has been tested in previous studies for a temperature range of $300-450^{\circ} \mathrm{C}$ in static conditions and has good accuracy with respect to theoretical calculation values [10]. There are two types of sensors that are used, namely sensor 1 which has an empty space on the inside, and sensor 2 where the empty space is filled by Aremco ceramic adhesive. The sensor housing as a protector is added to the dynamic condition to prevent the sensor from being carried by the flowing LBE in case the solid electrolyte is damaged (see Figure 4).

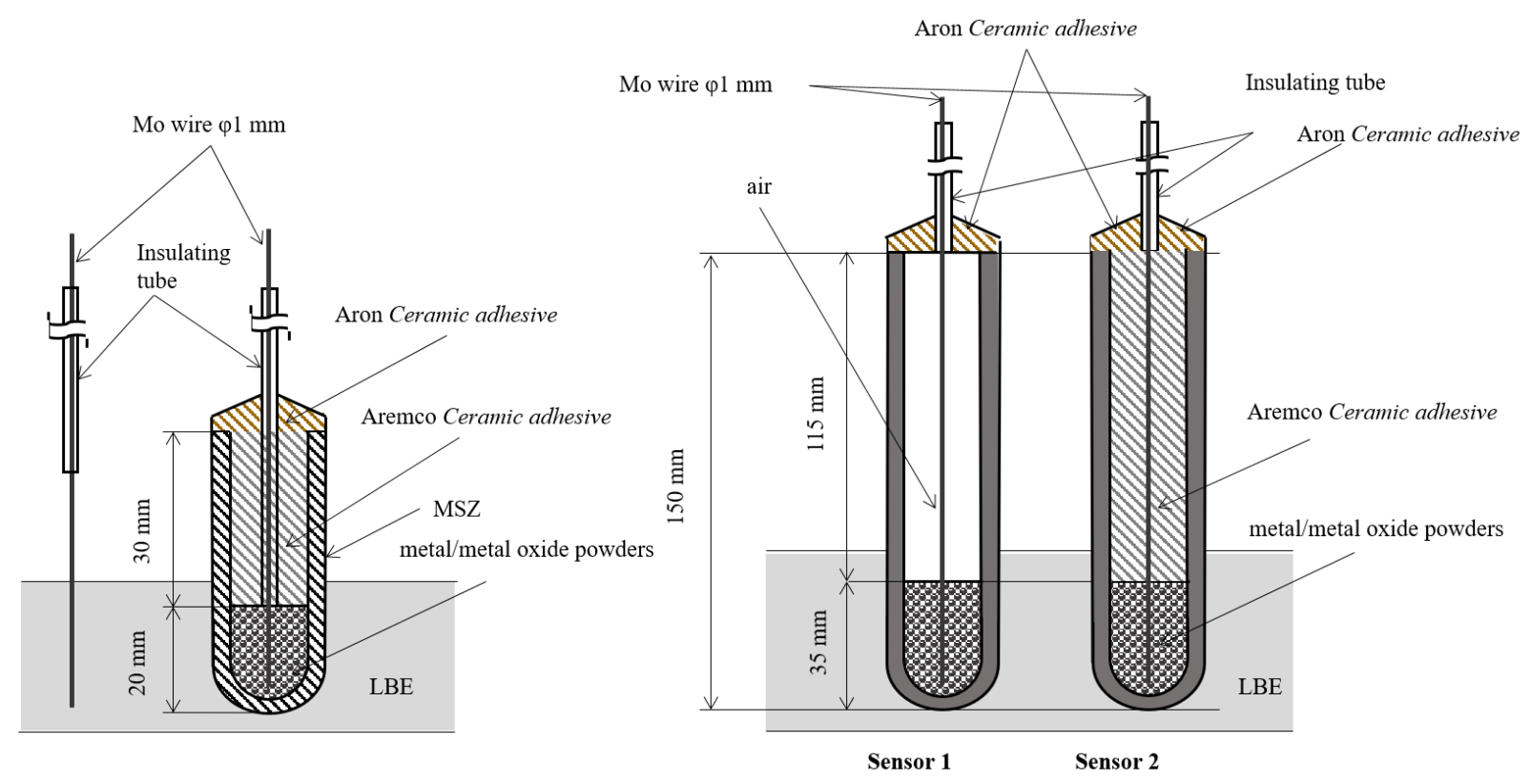

(a)

(b)

Figure 5. Structure of Oxygen sensor: (a) for LBE static condition, (b) for LBE dynamic condition

Solid electrolytes and wires that become working electrodes are immersed into liquid LBE, then potential differences will be generated. The potential difference must be measured using an electrometer that has a high input impedance value $(>1 \mathrm{G} \Omega)$ to prevent the influence of electric current on the circuit. Oxygen sensors measure the chemical potential difference, $\mu_{\mathrm{O} 2}$, which is produced between two electric leads. Galvani cells from the oxygen sensor in LBE liquid can be written as:

Electric lead 1, $\mathrm{O}_{2(\mathrm{~g})}\left(\mu_{\mathrm{O} 2}\right) \mid$ solid electrolyte $(\mathrm{SO}) \mid$ $\mathrm{O}_{2(\mathrm{~g})}\left(\mu_{\mathrm{O} 2, \text { Ref }}\right)$, Electric Lead 2,

The left side shows the oxygen potential in liquid LBE, while the right side shows a fixed and known oxygen potential on the reference electrode. Half the reaction can be written as

$\mathrm{O}_{2(\mathrm{~g})}+4 \mathrm{e}^{-}($electric lead $) \leftrightarrow 2 \mathrm{O}^{2-}(\mathrm{SO})$ at the cathode, oxygen gas and electron from the electric leads are consumed and $\mathrm{O}^{2-}$ ions are

produced. The oxygen ion is then transferred to solid electrolytes. The reverse process also takes place at the anode.

The relationship between the potential difference read by the electrometer and the chemical potential of oxygen can be written into

$E_{\mathrm{Cell}}=\frac{1}{4 F} \int_{\mu_{\mathrm{O}_{2}}}^{\mu_{\mathrm{O}_{2}}{ }^{\prime \prime}} \frac{\sigma_{i}}{\sigma_{i}+\sigma_{e}+\sigma_{h}} \mathrm{~d} \mu_{\mathrm{O}_{2}}$

where $\sigma$ is conductivity and subscript $i, e$, and $h$ denote ions, electrons and holes, respectively. The Ionic transference number, $t_{\mathrm{i}}$, described as [13]:

$t_{i} \approx \frac{\sigma_{i}}{\sigma_{i}+\sigma_{e}+\sigma_{h}}$ 
The relationship between the chemical potential of oxygen and oxygen partial pressure, $\mathrm{P}_{\mathrm{O} 2}$, can be written through this equation

$\mu_{\mathrm{O}_{2}}=\mu_{\mathrm{O}_{2}}{ }^{0}+R T \ln P_{\mathrm{O}_{2}}$

Thus the Equation (2) can be written as

$E_{\text {Cell }}=\frac{1}{4 F} \int_{P_{\mathrm{O}_{2}}}^{P_{\mathrm{O}_{2}} "} t_{i} \mathrm{~d}\left(\ln P_{\mathrm{O}_{2}}\right)$

The solid electrolyte material that used as a sensor must have a very high ion conductivity. The value of $t_{\mathrm{i}}$ for a material that has a very high ion conductivity is equal to one. Thus Equation (5) can be solved by taking the integration of the oxygen partial pressure at the working electrode until the oxygen partial pressure at the reference electrode is obtained:

$$
E_{\text {Cell }}=\frac{R T}{4 F} \ln \frac{P_{\mathrm{O}_{2}(\text { ref })}}{P_{\mathrm{O}_{2}(\text { wor })}}
$$

where $R$ is the gas constant, $T$ is the absolute temperature of the sensor, and shows the oxygen partial pressure at the reference electrode and the working electrode respectively. Equation (6) is also known as the Nernst equation. The relationship between the oxygen partial pressure for the pure $\mathrm{O}_{2}$ reference standard with oxygen activity, $a_{\mathrm{O}}$, at a pressure of 1 atm can be written as

$$
\left(P_{\mathrm{O}_{2}}\right)^{\frac{1}{2}}=a_{\mathrm{O}}
$$

so the Nernst equation in Equation (6) can be written as

$$
E_{\text {Cell }}=\frac{R T}{2 F} \ln \frac{\left(a_{\mathrm{O}, \text { ref }}\right)}{\left(a_{\mathrm{O}, \mathrm{LBE}}\right)}
$$

The oxidation reaction of $\mathrm{Fe}$ in the $\mathrm{Fe} / \mathrm{Fe}_{3} \mathrm{O}_{4}$ reference electrode in equilibrium state can be written as

$$
\begin{aligned}
& \frac{3}{2} \mathrm{Fe}_{(\mathrm{s})}+\mathrm{O}_{2(\mathrm{~g})} \square \frac{1}{2} \mathrm{Fe}_{3} \mathrm{O}_{4(\mathrm{~s})} \\
& \frac{1}{2} \Delta G_{\mathrm{Fe}_{3} \mathrm{O}_{4}}^{0}+R T \ln \frac{a_{\mathrm{Fe}_{3} \mathrm{O}_{4}}^{1 / 2}}{a_{\mathrm{Fe}}^{3 / 2} a_{\mathrm{O}_{2}}}=0
\end{aligned}
$$

the activity of pure metal and metal oxide, $\mathrm{Fe}$ and $\mathrm{Fe}_{3} \mathrm{O}_{4}$, is equal to unity, therefore, $\mathrm{O}_{2}$ activity becomes proportional to its partial pressure

$$
\frac{1}{2} \Delta G_{\mathrm{Fe}_{3} \mathrm{O}_{4}}^{0}+R T \ln \frac{1}{P_{\mathrm{O}_{2}}}=0
$$

by using the Sieverts law the activity in Fe can be determined by Equation (7). Thus, the oxygen activity in the reference electrode can be calculated by equation

$$
a_{0, \mathrm{ref}}=\exp \frac{\Delta G_{\mathrm{Fe}_{3} \mathrm{O}_{4}}^{0}}{4 R T}
$$

The oxygen activity in liquid LBE can be written in the form of oxygen concentration, $C_{\mathrm{O}}$, and oxygen partial pressure as written in the following equation

$a_{\mathrm{O}}=\gamma_{\mathrm{O}} C_{\mathrm{O}}=\frac{C_{\mathrm{O}}}{C_{\mathrm{O}, \mathrm{s}}}=\left(\frac{P_{\mathrm{O}_{2}}}{P_{\mathrm{O}_{2}, \mathrm{~s}}}\right)^{\frac{1}{2}}$

where $\gamma_{O}$ is the activity coefficient and subscript 's' shows the saturation state at LBE. Equation (13) can be rewritten to

$$
\left(P_{\mathrm{O}_{2}}\right)^{\frac{1}{2}}=\gamma_{\mathrm{O}} C_{\mathrm{O}}\left(P_{\mathrm{O}_{2}, \mathrm{~s}}\right)^{\frac{1}{2}}
$$

The oxygen partial pressure under saturation conditions at liquid LBE can be written as

$$
\left(P_{\mathrm{O}_{2}, \mathrm{~s}}\right)^{\frac{1}{2}}=C_{\mathrm{O}, \mathrm{s}} \exp \frac{G_{\mathrm{O}, \mathrm{LBE}}^{\mathrm{EX}}}{R T}
$$

where $G_{\mathrm{O}, \mathrm{LBE}}^{\mathrm{EX}}$ is excess molar Gibbs free energy from dissolving oxygen at LBE. The oxygen partial pressure in LBE can be obtained by substituting Equation (15) to Equation (14), so that the oxygen activity in LBE can be calculated by the equation

$a_{\mathrm{O}, \mathrm{LBE}}=C_{\mathrm{O}} \exp \frac{G_{\mathrm{O}, \mathrm{LBE}}^{\mathrm{EX}}}{R T}$

by substituting Equations (12) and (16) to Equation (8), the relation between the potential difference and the oxygen concentration at LBE is obtained.

$E_{\text {cell }}=\frac{R T}{2 F}\left(\frac{\Delta G_{\mathrm{Fe}_{3} \mathrm{O}_{4}}^{0}}{4 R T}-\frac{G_{\mathrm{O}, \mathrm{LBE}}^{\mathrm{EX}}}{R T}-\ln C_{\mathrm{O}}\right)$ 
The $C_{\mathrm{O}}$ value when the oxygen saturation condition at LBE is obtained using the following relation [15] $\log C_{\mathrm{O}, \mathrm{S}}(\mathrm{wt} \%)=2.2-4416 / T(T \leq 1023 \mathrm{~K})(18)$

\section{RESULTS AND DISCUSSION}

\section{In LBE Static Condition}

The results of measurements using an oxygen sensor in liquid LBE are shown in Figure 6. Four experimental data (round blue) were obtained in the temperature range $450-600{ }^{\circ} \mathrm{C}$. Theoretical values are presented through black lines.

LBE steady state is obtained after the LBE temperature is left idle for approximately 12 hours at each working temperature. The value of $E$ presented in Figure 6 is the average value in the last 3 hours. The value of theoretical $E$ is obtained from calculations using Equation (14). Good agreement between experimental data and theoretical calculations as seen in Figure 6 was successfully

obtained. The difference between experiment and theory is quite small and the maximum error value of each sensor is below $10 \%$. The lowest accuracy occurs when the sensor is tested at $450{ }^{\circ} \mathrm{C}$ with a difference of $32 \mathrm{mV}$ and an error percentage of $8.5 \%$. Meanwhile, the best accuracy occurs when the sensor is tested at $550{ }^{\circ} \mathrm{C}$ with a difference of 5 $\mathrm{mV}$ and an error percentage of about $1.3 \%$. These results indicate that the sensor with the $\mathrm{Fe} / \mathrm{Fe}_{3} \mathrm{O}_{4}$ reference electrode can detect the upper limit of the oxygen concentration at LBE which is in balance with the potential formation of $\mathrm{PbO}$.

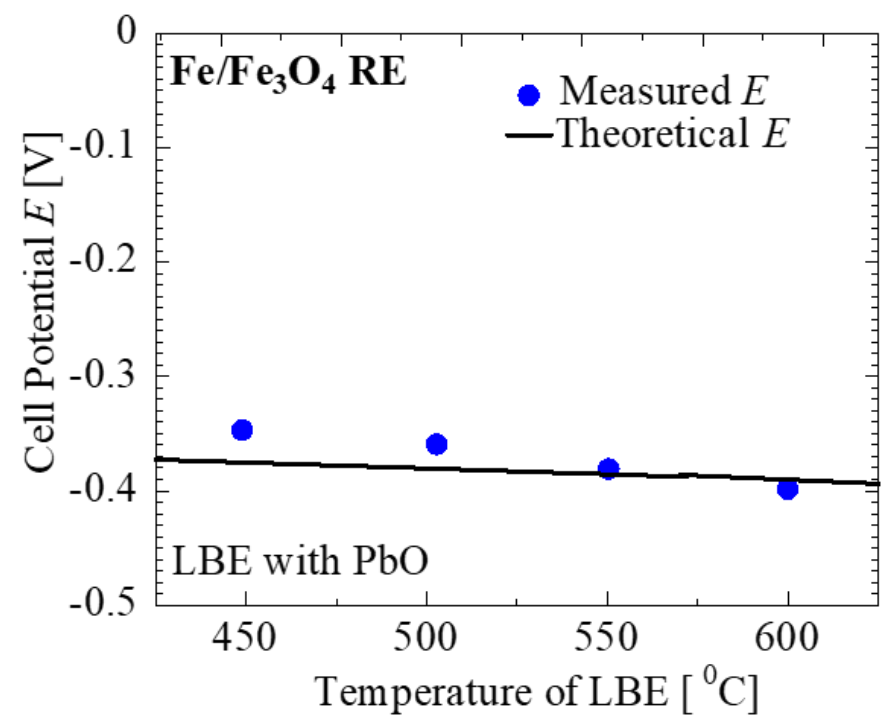

Figure 6. Cell potentual after steady-state condition was obtained in LBE with $\mathrm{PbO}$

\section{In LBE Dynamic Condition}

Experiments on LBE dynamic conditions are carried out using two types of sensors as seen in Figure $5 \mathrm{~b}$. The experimental results for dynamic conditions can be seen in Figure 7. Figure 7 shows the profile of the potential difference results in sensors 1 and 2 with respect to time and also the profile of the LBE flow rate with respect to time. The temperature of the oxygen sensor from the thermocouple reading shows a value that is around $390^{\circ} \mathrm{C}$. Blue, black, and red lines represent the potential difference in sensor 1 , sensor 2 , and the temperature of the oxygen sensor at LBE liquid respectively. 

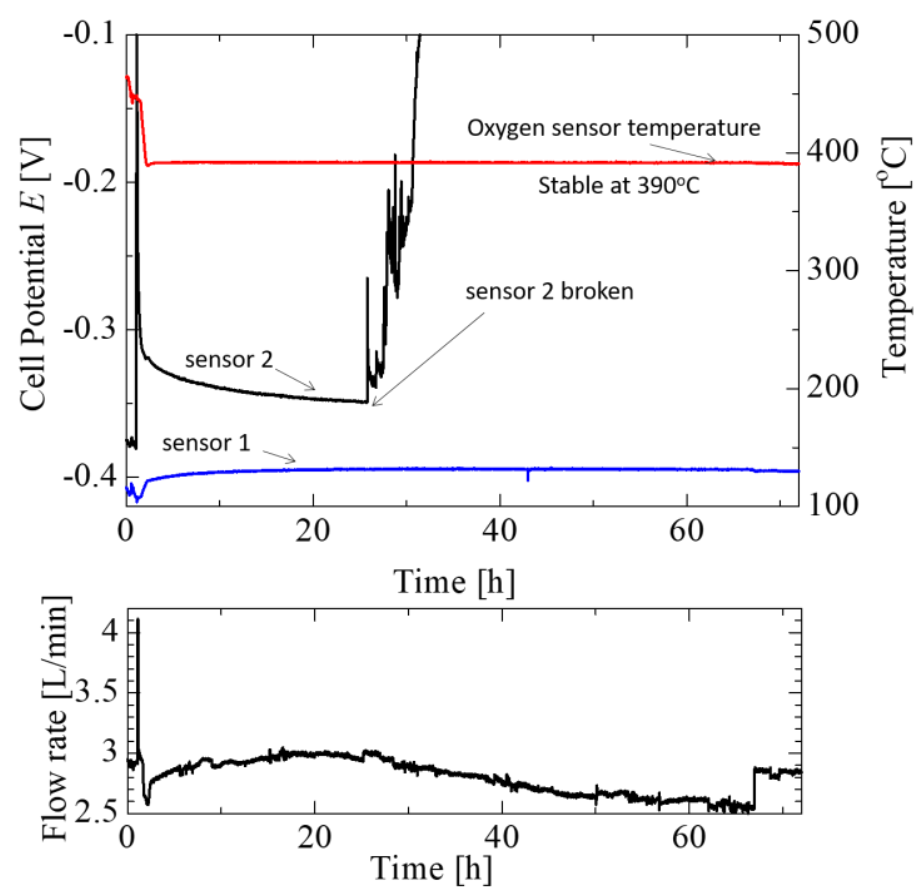

Figure 7. Profile of potential difference in experimental results and LBE flow rate with time

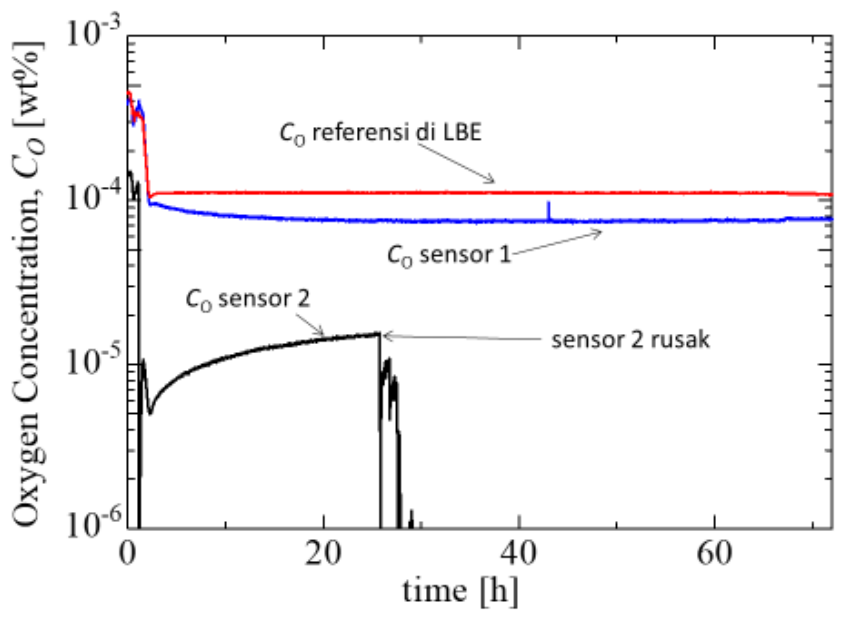

Figure 8. Profiles of oxygen concentration in liquid LBE with time

The experimental results for 72 hours show that sensor 1 can work well until the end of the time of data retrieval. Abnormal conditions are seen in sensor 2. After about 24 hours of work there is damage to the sensor 2 . The profile of the potential difference appears to increase dramatically and goes to the value of 0 . It is suspected that there has been a kind of short circuit when installing sensor 2 or during manufacture, because after the sensor oxygen taken from the $\mathrm{Pb}-\mathrm{Bi}$ loop does not find damage to the outside of the solid electrolyte. So the potential difference value shown by sensor 2 becomes invalid.

Sensor 1 can work well in a range of 72 working hours. The average value obtained by the sensor is $-391.20 \mathrm{mV}$. Changes in the liquid LBE flow rate are also shown in Figure 7. The output signal from this sensor is also not affected by fluctuations in the LBE flow rate. Sensor 1 still shows a constant value even though the flow rate 
changes. So it can be concluded that the oxygen sensor with the $\mathrm{Fe} / \mathrm{Fe}_{3} \mathrm{O}_{4}$ reference electrode can work well not only in static conditions but also in dynamic conditions.

To check the oxygen concentration in the $\mathrm{Pb}$ Bi loop, the results of the cell potential $E$ are converted to oxygen concentrations according to Equation (17). Figure 8 shows how the oxygen concentration in the $\mathrm{Pb}$ - $\mathrm{Bi}$ loop. In accordance with the previous explanation, due to damage to sensor 2 , the result of sensor 2 is considered invalid. The result of sensor 1 (blue line color) shows that the readout oxygen concentration is slightly below the reference oxygen concentration in the oxygen saturation condition at liquid LBE. Oxygen concentration was obtained from the measurement results of $6.10 \times 10^{-5} \mathrm{wt} \%$ while the oxygen concentration under oxygen saturation conditions was $1.07 \times 10^{-4} \mathrm{wt} \%$. A small difference from the reference conditions with the measurement results can be caused by the impurity content of LBE as a result of corrosion products which are dissolved together with LBE flow.

\section{CONCLUSION}

Fabrication and testing of oxygen sensors in liquid LBE at a temperature of $450-600^{\circ} \mathrm{C}$ for static conditions and at temperature of $390^{\circ} \mathrm{C}$ for dynamic conditions have been successfully carried out. From the results of experiments, some conclusions can be made: Oxygen sensors with reference electrode $\mathrm{Fe} / \mathrm{Fe}_{3} \mathrm{O}_{4}$ can be used to measure liquid oxygen concentration in LBE both in static and dynamic conditions; In static conditions, the results of measurements and theoretical calculations have different values with an error percentage below $10 \%$; In dynamic conditions, the measurement results show the oxygen concentration which is close to the saturation oxygen concentration value in LBE.

\section{REFERENCES}

[1] L. Cinotti et al., Lead-cooled system design and challenges in the frame of Generation IV International Forum, J. Nucl. Mater 415, 245, 2011.

[2] V. Sobolev, Thermophysical properties of lead and lead-bismuth eutectic, J. Nucl. Mater 362, 235, 2007.

[3] G. Muller et al., Control of oxygen concentration in liquid lead and lead bismuth, J. Nucl. Mater 321, 256, 2003.

[4] J. Konys et al., Oxygen measurements in stagnant lead-bismuth eutectic using electrochemical sensors, J. Nucl. Mater 249, 249, 2004.

[5] M. Kondo and M. Takahashi, Study on control of oxygen concentration in lead bismuth flow using lead oxide particles, $J$. Nucl. Mater 357, 97, 2006.

[6] C Schroer, O. Wedemeyer, and J. Konys, Aspects of minimizing steel corrosion in liquid lead-alloys by addition of oxygen, $\mathrm{Nucl}$ Eng Des 241, 4913, 2011.

[7] J. Lim et al., Control of dissolved oxygen in liquid LBE by electrochemical oxygen pumping, Sens Actuators B Chem 204, 388, 2014.

[8] C. Schroer et al., Design and testing of electrochemical oxygen sensors for service in liquid lead alloys, J. Nucl. Mater 415, 338, 2011.

[9] P. M. Adhi and M. Takahashi, Parametric Study on Electromotive Force of Oxygen Sensor in Lead-Bismuth Eutectic, Proc. of ICONE 23 (May 18-20, Chiba), 1951, 2015

[10] P. M. Adhi et al., Electrochemical Impedance Analysis on Solid Electrolyte Oxygen Sensor with Gas and Liquid Reference Electrodes for Liquid LBE, Energy Procedia 131, 420, 2017.

[11] P. M. Adhi, M. Kondo, and M. Takahashi, Performance of solid electrolyte oxygen sensor with solid and liquid reference electrode for liquid metal. Sens Actuators $B$ Chem 241, 1261, 2017.

[12] P. M. Adhi, M. Kondo, dan M. Takahashi, Study on Performance of Oxygen Sensors with Solid and Liquid Reference Electrodes in Liquid LBE with The Parameters of Oxygen Potential and Temperature, Proc. ICAPP 2017 (April 24 - 28, Fukui-Kyoto, Japan) paper 17124, 2017.

[13] Q. Hu et al., T, Lifetime of the internal reference oxygen sensor, Solid State Ionics 240, 34, 2013.

[14] M. Takahashi et al., Proc. of ICONE 8 ( April 2-6, Baltimore, MD), 8507, 2000.

[15] C. Schroer C and J. Konys, Physical Chemistry of Corrosion and Oxygen Control in Liquid Lead and Lead-Bismuth Eutectic, Forschungszentrum Karlsruhe $\mathrm{GmbH}$, Karlsruhe, Germany, 22, 2007. 